\title{
Effectiveness of an Individual School-based Intervention for Children with Aggressive Behaviour: A Randomized Controlled Trial
}

\author{
Sabine Stoltz, Monique van Londen, Maja Deković, Bram O. de Castro and Peter Prinzie \\ Utrecht University, The Netherlands
}

John E. Lochman

University of Alabama, USA

\begin{abstract}
Background: For elementary school-children with aggressive behaviour problems, there is a strong need for effective preventive interventions to interrupt the developmental trajectory towards more serious behaviour problems. Aim: The aim of this RCT-study was to evaluate a school-based individual tailor-made intervention (Stay Cool Kids), designed to reduce aggressive behaviour in selected children by enhancing cognitive behavioural skills. Method: The sample consisted of 48 schools, with 264 fourth-grade children selected by their teachers because of elevated levels of externalizing behaviour (TRF T-score $>60$ ), randomly assigned to the intervention or no-intervention control condition. Results: The intervention was found to be effective in reducing reactive and proactive aggressive behaviour as reported by children, mothers, fathers or teachers, with effect sizes ranging from .11 to .32 . Clinically relevant changes in teacher-rated externalizing behaviour were found: the intervention reduced behaviour problems to (sub) clinical or normative levels for significantly more children than the control condition. Some aspects of problems in social cognitive functioning were reduced and children showed more positive self-perception. Ethnic background and gender moderated intervention effects on child and teacher reported aggression and child response generation. Conclusions: The results of this study demonstrate the effectiveness on outcome behaviour and child cognitions of an individual tailor-made intervention across informants under realworld conditions.
\end{abstract}

Keywords: School-based intervention, randomized controlled trial, reactive and proactive aggression, social cognitions, self-perception.

\section{Introduction}

Externalizing behaviours, such as disobedience, aggression and lying, are the most common form of maladjustment in school aged children (Dishion and Patterson, 2006). Whereas the

Reprint requests to Sabine Stoltz, Research Centre Psychosocial Development in Context, Utrecht University, P.O. Box 80.140, 3508 TC Utrecht, The Netherlands. Email: s.e.m.j.stoltz@uu.nl 
normative level of aggressive behaviour declines when children are between 4 and 9 years old (Campbell, Spieker, Burchinal and Poe, 2006), for a small group of children (5\% to $11 \%$ ) the aggressive behaviour remains stable and becomes problematic (Prinzie, Onghena and Hellinckx, 2005). This is especially true for children with elevated aggression at the start of elementary school (Broidy et al., 2003). Several developmental trajectory studies indicate that stable aggressive behaviour in elementary school places children at risk for future difficulties such as rejection by peers, school failure, and more serious externalizing problems (Moffit, 1993; Patterson, Reid and Dishion, 1992). Over time, these children also have increased risk of developing diagnosable psychopathology (Oppositional Defiant Disorder and Conduct Disorder), substance abuse, and delinquency in adolescence (Broidy et al., 2003). Moreover, in an 18-year longitudinal study of 10-year-old children, it has been demonstrated that costs to society are 10 times higher for children with elevated levels of externalizing behaviour compared to children without elevated levels of externalizing behaviour (Scott, Knapp, Henderson and Maughan, 2001). Given these findings, there is a strong need for effective preventive interventions designed to interrupt the developmental trajectory towards more serious behaviour problems for elementary school-children with aggressive behaviour problems (Buckley, 2009).

The aim of the present study was to test the effectiveness of an individual school-based preventive cognitive behavioural training (Stay Cool Kids) to reduce aggressive behaviour among indicated elementary school children. The intervention was originally developed in real world practice and is routinely used in clinical practice. However, its effectiveness has not yet been examined. Therefore, we aimed to study the effectiveness of this program as actually delivered in daily practice.

Much research has been dedicated to understanding the etiology of aggression (e.g. Bandura, 1973; Patterson, 2002). One of the well grounded models explaining the development and persistence of aggressive behaviour is the social information processing model, based on social cognitive theory (Dodge, 1986). According to this model aggressive children have problems in processing information, which lead to inappropriate responses in social settings.

Stay Cool Kids aims to prevent externalizing behaviour problems by targeting problems in social information processing. In this model behaviour is seen as a result of six mental steps: (1) encoding of cues; (2) interpretation of these cues; (3) clarification of goals; (4) response access or construction; (5) response decision; and (6) enacting selected responses. A set of internal social schemas of others and self, derived from individual experiences, is the knowledge base for the social information processing steps (Lemerise and Arsenio, 2000). It has been suggested that children with aggressive behaviour show problems in their social information processing patterns (Crick and Dodge, 1994; Dodge, 1986). For example, at the encoding stage, aggressive children attend to other cues from social situations (Horsley, de Castro and van der Schoot, 2010). When making interpretations, they over attribute hostile intentions to peers and adults when provoked (de Castro, Veerman, Koops, Bosch and Monshouwer, 2002). They consequently hold more instrumental and less affiliative goals (Salmivalli, Kaukianinen, Kaistanieme and Lagerspetz, 1999), generate less prosocial solutions and are more likely to opt for an aggressive solution (Matthys and Lochman, 2005). More specifically, children showing more reactive aggression (which can be seen as an angry, emotional reaction to a presumed threat or provocation) specifically make more hostile attributions, whereas proactive aggressive children (planned "cold blooded" aggression 
to dominate or intimidate) evaluate aggressive responses more positively (Crick and Dodge, 1994; de Castro, Merk, Koops, Veerman and Bosch, 2005; Dodge, 1991). In addition to these aspects of social information processing, aggressive children seem to differ from their peers in social cognitive schemas, notably in their self-perception. From a social learning theory perspective (Bandura, 1973), lasting experiences of coercive parenting, conflicts, and rejection by peers can make children uncertain of their worth and competence. This is reflected in highly variable self-esteem and self-perceived social competence in aggressive children. Apparently, many aggressive children with such uncertain self-views feel they need to maintain a facade of high status to others (and perhaps even themselves). When their competence or worth is challenged these children try to defend their uncertain self-regard from external threats (e.g. Bushman et al., 2009). Thus, uncertainty about one's worth or competencies can lead to perceiving others as threatening, hostile and rejecting, which in turn can cause hostile, defensive and aggressive behaviour (de Castro, Brendgen, van Boxtel, Vitaro and Schaepers, 2007). These behaviours supposedly lead to rejection by others, which confirm the child's uncertainty about himself (Donnellan, Trzesniewski, Robins, Moffit and Caspi, 2005). Especially proactive aggression in children has been suggested to be related to distorted self-perceptions (Salmivalli, 2001).

Interventions based on the social information processing model (e.g. Brainpower program; Hudley and Graham, 1993; Coping Power Program, Lochman and Wells, 2002a) have several general characteristics. They explicitly provide training on one or more of the social information processing steps (Crick and Dodge, 1994). Trainers put emphasis on cognitive skills or thinking processes, and they make use of structured tasks to teach children cognitive skills that can be applied in social situations (Wilson and Lipsey, 2006). These social information processing interventions are effective $(d=.26)$ in reducing aggressive behaviour of school-age children who show increased levels of externalizing behaviour $(k=47$ studies, Wilson and Lipsey, 2006). However, large differences in effect sizes across studies were found, which can be explained by the considerable variability among intervention programs. Interventions for children with externalizing behaviour were found to be most effective when they focused on higher risk children in regular education (Wilson and Lipsey, 2006), individually delivered and better implemented (Wilson and Lipsey, 2007).

The Stay Cool Kids program includes a number of the characteristics that have been suggested to be most promising. First, it is a school-based intervention, aimed at children displaying a (sub) clinical level of aggression according to their teachers, within regular education. Schools are excellent locations for prevention activities as children can be reached in a systematic and efficient way. Moreover, stable aggressive behaviours start to impair social and academic functioning at school age, and since school is the most common setting for social interaction, it is also the place where much interpersonal aggression among children can occur. Offering prevention activities in a school setting may make treatment more acceptable to parents (Catron and Weiss, 1994) and there is no dependence on parents remembering their child's appointments. Besides, locating the intervention at school increases the likelihood of generalization and maintenance of treatment effects to the natural environment (Evans, Langberg and Williams, 2003). School-based interventions for children indicated with externalizing behaviour problems are in general effective $(k=108$ studies, $d=.29$; Wilson and Lipsey, 2007).

Second, Stay Cool Kids is an indicated-type intervention that targets children at higher risk for developing more serious problem behaviours as a consequence of early onset aggressive 
behaviour. Interventions can be distinguished into three categories: universal, selective, and indicated preventive interventions (Saxena, Jané-Llopis and Hosman, 2006). Universal preventive interventions are offered to a whole population, not identified because of elevated levels of problem behaviour. For example, the KiVa anti-bullying intervention, in which lessons to prevent bullying in schools are offered to all students in a school (Salmivalli, Kärnä and Poskiparta, 2011). Selective prevention is for those individuals or subgroups at higher risk for developing psychosocial problems, because of biological, psychological or social risk factors. For instance, the Strengthening Families Program, to prevent behaviour problems in children living in high-risk families (Kumpfer and Alvarado, 1995). Finally, indicated prevention is for at-risk individuals who are displaying symptoms of behavioural disorders, but who do not yet meet diagnostic criteria. For example, the Coping Power Program, for children with elevated levels of externalizing behaviour (Lochman and Wells, 2002b). School-based interventions exist at these three different levels (Reinke, Splett, Robeson and Offutt, 2009; Walker et al., 1996). School-based universal interventions are often "curriculum" interventions, in which lessons that focus on reducing aggression or violence in schools can be given to a whole class or school population (e.g. Promoting Alternative Thinking Strategies; Greenberg, Kusche, Cook and Quamma, 1995). Children at higher risk might not respond to universal interventions, so for these children selective preventive interventions can be offered (e.g. Primary Mental Health Project; Cowen et al., 1996). For a small group of children, displaying more severe problems, indicated or targeted interventions, as Stay Cool Kids, might be more beneficial (Gottfredson and Wilson, 2003). An important advantage of targeted interventions, in contrast to universal and selective interventions, is that they can be adapted for individual children in need of more than a standard curriculum (Gottfredson and Wilson, 2003).

Third, Stay Cool Kids is an individual intervention and therefore may prevent children from exposure to deviancy training. Most of the targeted interventions for aggressive behaviour take place in groups of selected children, although several studies (e.g., Dishion, McCord and Poulin, 1999) indicated that peer-group interventions may increase problem behaviour, especially for high-risk youth. In addition, it is more difficult to focus on specific needs and difficulties of an individual child in group interventions. However, in a meta-analysis on the effectiveness of individually delivered indicated school-based interventions for externalizing behaviour problems at elementary schools we found that only 24 studies evaluated effects in the last 35 years ( $k=24$ studies, $d=.30$; Stoltz, van Londen, Deković, de Castro and Prinzie, in press). Stay Cool Kids is not just an individually delivered intervention, it is also an individualized (adaptive) intervention, which means that it can be adapted to particular individual differences, for example to cultural values or gender of the child. It has been recommended that an emphasis should be placed on tailoring interventions to specific youth (Frick, 2000; La Greca, Silverman and Lochman, 2009).

Recently, it has been found that implementation of an intervention in schools is highly dependent on the skills of school staff, funding, and the capacity to provide coaches for the program (Loman, Rodriguez and Horner, 2010). A unique aspect of the Stay Cool Kids program is that it is provided to children in the school setting by professional mental health care workers, who work intensively together with school staff. It has been suggested that prevention programs offered by trained interventionists are more effective than programs delivered by classroom teachers (Baranowski, Cullen, Nicklas, Thompson and Baranowski, 2002), because of more and higher quality training (Gottfredson and Gottfredson, 2002). Moreover, indicated individual interventions, as Stay Cool Kids, are time-consuming and 
teachers may not be able to devote as much time to providing one-to-one interventions. Additionally, teachers often have their own "history" with a child displaying elevated levels of externalizing behaviour, since these children disrupt classroom routines, detract from learning opportunities, and have negative influences on classmates (McConaughy and Skiba, 1993). Therefore, it might be beneficial to let an independent trainer conduct the intervention.

Finally, to make sure that a program is effective in changing child behaviour, it is important to involve the context as well (e.g. Incredible Years; Reid and Webster-Stratton, 2001). In the Stay Cool Kids training parents and teachers are involved with the goals of helping the child with generalization of new learned skills and behaviour to the school and home setting.

The present study extends previous intervention studies in several ways. First, it focuses on an intervention that includes several specific promising characteristics: it is an indicatedtype school-based intervention, delivered by trained professionals on an individual basis that still involves the context. Second, in contrast to studies concerning optimally implemented "demonstration programs" for research purposes, the present study focuses on a routinely delivered program in daily practice, and therefore can give information about effectiveness under real-world conditions (e.g. Hautmann et al., 2009; Kratochwill and Shernoff, 2004). Third, in addition to general effectiveness, we also examined for whom the intervention works best by including gender and ethnic background as moderators. Little is known about possible ethnic differences in response to the intervention, despite the inclusion of ethnic minority families in intervention study samples (Yasui and Dishion, 2007). As a result of different parental socialization practices, cultural values and traditions, possible negative experiences with discrimination, and experienced challenges of the acculturative process, it is important to include ethnicity as moderator (Kellam and van Horn, 1997; Yasui and Dishion, 2007). Moreover, despite numerous studies showing differences in manifestations of aggression for boys and girls (e.g. Crick and Grotpeter, 1995), gender differences in intervention effects are less clear (Brestan and Eyberg, 1998). Fourth, multiple informants (children, mothers, fathers and teachers) and multiple types of outcome behaviours (reactive and proactive aggression, social cognitions and self-perception) are included to provide a comprehensive view of changes in child behaviour after the intervention (Achenbach, McConaughy and Howell, 1987; Grietens et al., 2004). Primary outcome variables are reactive and proactive aggression. It has been suggested that these two types of aggression require different interventions (Vitaro, Brendgen and Tremblay, 2002). We expect Stay Cool Kids to affect reactive aggression, since the training provides exercises on modifying encoding and interpretation of social cues and generating responses to social provocations. We also expect changes in proactive aggression, since the training focuses on modifying choosing responses to react and enacting behaviour. Because of the social cognitive basis of this intervention, we examine in addition to aggressive behaviour changes in child self-perception, hostile intent attribution, response generation and response evaluation and we expect that children will have more optimal levels of self-perception, will attribute less hostile intent, and will be more likely to select prosocial solutions.

Finally, clinically relevant changes are examined in addition to intervention effects on mean levels of outcome (e.g. Scott, 2005). Clinically relevant changes in every day life, in addition to the classical approach of evaluating intervention effects, are rarely tested in intervention studies (Kendall, 1999). Therefore, in the present study we investigated for how many children externalizing behaviour actually changed from a (sub) clinical level to a normative level (i.e. recovery; Ogles, Lunnen and Bonesteel, 2001). 


\section{Method}

\section{Design}

Figure 1 shows the randomization process and participant flow. Forty-eight elementary schools (i.e. 4-th grade classrooms), in two urban regions in the Netherlands, were randomly assigned to one of three groups. Each group of schools participated in the intervention as well as in the control condition, but in a different order. In group 1, schools were assigned to the intervention condition in the first and second year and to the control condition in the third year. In group 2, schools received the intervention in the first year, were in the control condition in the second year, and again in the intervention condition in the third year. In group 3 , schools were assigned to the control condition in the first year, and were in the intervention condition in the second and third year. Thus, treatment condition was randomized, and each school provided both intervention and control condition children. In this way we ensured that intervention effects could not be due to school factors, because the same schools were in both conditions. Moreover, schools were more willing to participate in the control condition when they were assured of receiving 2 years of training. In different years, different teachers selected children. However, in some schools the same teachers selected children for the 3 years of the study. There were two assessment periods: prior to the beginning of the intervention (T1), and at intervention termination (after 11 weeks, T2). The study was approved by the Dutch Central Committee on Research Involving Human Subjects.

To control for the design effect (randomization at school level could lead to biased standard errors), we computed the design effect as recommended by Muthén (2000), which is expresses as $d=1+\rho(c-1)$, where $\rho$ is the average intraclass correlation (.18) and $c$ is the common cluster size (i.e. the average number of children per school, 4.2). The design effect was 1.58, which is smaller than 2.0 and can therefore be ignored (Muthén, 2000).

\section{Procedure}

First, parents of all children in fourth grade received a general information letter about the study and a consent form to give permission for teachers to fill out the Teacher Report Form (TRF; age 6-18; Achenbach, 1991, see Measures) about their child. Teachers then nominated children from their classes with the highest levels of externalizing behaviour (the top 30\%) and filled out the 32-item externalizing scale of the TRF. Next, researchers selected children based on their T-scores. The inclusion criterion was a T-score $>60$, indicating a (sub) clinical level of externalizing behaviour, which places children at risk for various negative outcomes. Other studies used similar criterion as high-risk indicators in prevention studies with elementary school-aged children (Lochman and CPPRG, 1995). If a child was selected, primary caretakers were contacted by phone and in meetings at school to gather their informed consent to participate in this study. After consent was obtained, the baseline preassessment was conducted. Children's measures were collected in their school settings and were administered to children by trained research assistants. Parents received questionnaires in meetings at school or by mail. They were asked to return the questionnaires within a week and were reminded by teachers and research staff if needed. Children received a small gift for their participation. Parents and teachers received a small monetary reimbursement for their time. 


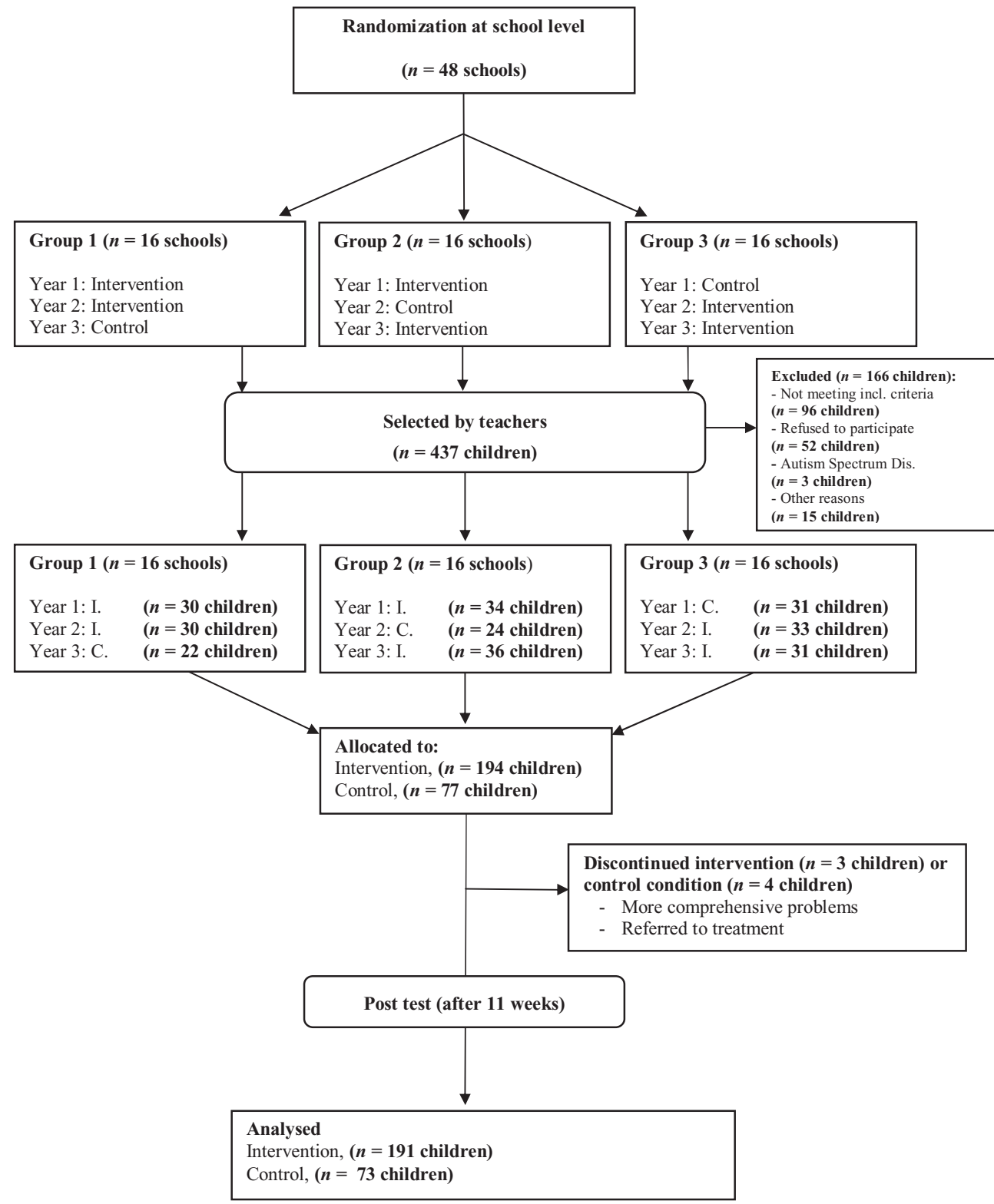

Figure 1. Flow chart of randomization design

\section{Participants}

Teachers initially selected 437 children. Of these selected children, some children did not meet the inclusion criteria $(n=96)$, some parents refused to participate $(n=52)$, some children already participated in other forms of youth care $(n=15)$ or were diagnosed with Autism 
Table 1. Sample characteristics by condition

\begin{tabular}{lcc}
\hline & $\begin{array}{c}\text { Intervention Group } \\
(n=191)\end{array}$ & $\begin{array}{c}\text { Control Group } \\
(n=73)\end{array}$ \\
Sample characteristics & $M(S D)$ & $7(S D)$ \\
\hline Child & $72 \%$ & $70 \%$ \\
Gender (\% boys) & $32 \%$ & $20 \%$ \\
Ethnicity (\% immigrant) & 66 & 67 \\
TRF selection t-scores (externalizing) & $10.1(.54)$ & $10.1(.49)$ \\
Age (years) & & \\
Parent & $41.1(4.24)$ & $38.8(4.51)$ \\
Age (years) & $43.4(4.94)$ & $43.6(6.23)$ \\
- Mother & & \\
- Father & $80 \%$ & $71 \%$ \\
Civil status (\%) & $6 \%$ & $8 \%$ \\
- Married & $14 \%$ & $12 \%$ \\
- Living together & & \\
- Divorced & $10 \%$ & $5 \%$ \\
Education $(\%)$ & $30 \%$ & $25 \%$ \\
- Primary (or less) & $34 \%$ & $40 \%$ \\
- Secondary & $16 \%$ & $20 \%$ \\
- Intermediate vocational & $13 \%$ & $11 \%$ \\
- Higher vocational & $2.50(1.00)$ & $2.47(1.10)$ \\
- University & &
\end{tabular}

Spectrum Disorder $(n=3)$ (see Figure 1). Three children discontinued the intervention, four children discontinued in the control condition. Children in the control condition did not receive any intervention or received care as usual (e.g. remedial teaching, universal remediation programs). Moreover, the Stay Cool Kids intervention is offered to children in the control condition after the final assessment when still necessary (a year after treatment termination).

There were no significant differences in child gender or TRF score between parents who consented to participate and those who did not. Children in the intervention and control group did not differ significantly on demographic characteristics at Time 1.

The final sample consisted of 264 children ( $n=191$ boys, $n=73$ girls), 197 mothers, 130 fathers, and 155 teachers at Time 1. For 114 children both parents filled in the questionnaire at Time 1. For 83 children only mothers, and for 14 children only fathers filled in the questionnaire at Time 1 . As can be seen in Table 1, most children (76\%) are from doubleparent families. During the 3 -year period most teachers $(n=79)$ had only one child receiving the intervention in their class, whereas some teachers had two $(n=54)$, three $(n=19)$, or four $(n=5)$ children from their classes being selected by researchers for the intervention. As a result, for 185 children another classmate also participated in the same condition, but children always participated individually. Table 1 lists demographic characteristics for the intervention $(n=191)$ and control $(n=73)$ group. 
Consistent with other studies on immigrant groups in the Netherlands (Eichelsheim et al., 2009), a child was considered "immigrant" if either the child or one of the parents was born in another country than the Netherlands. If both child and parents were born in the Netherlands, the child was considered "native Dutch". In total, $27 \%$ of the participating children were immigrants.

At Time 2, 99\% of the children in the intervention actually had completed the intervention. All children who completed the intervention filled out the questionnaires at Time $2(n=264)$. For 24 children (9\%), teachers did not complete the questionnaire at Time 2, because of lack of time or personal circumstances. These missing values at Time 2 were completely random (Little's MCAR test: $\chi^{2} / 2=.05, p=.95$ ). For both mothers (T1 $n=67$, T2 $n=93$ ) and fathers (T1 $n=134$, T2 $n=164$ ) missings were also completely random (Mothers: Little's MCAR test: $\chi^{2} / 7=.99, p=.44$; Fathers: Little's MCAR test $\chi^{2} / 4=.85, p=.49$ ). We did not use listwise deletion as it can result in discarding a large proportion of the data, which can lead to biased results, because the power of the study decreases. Multiple imputation is currently recommended as a modern missing data handling technique (Baraldi and Enders, 2010). We used Multiple Imputation techniques module of LISREL8.7 with the Expected Maximization (EM) algorithm. Imputed data were used in further analyses.

\section{Intervention}

The Stay Cool Kids training is a social cognitive intervention that focuses on reciprocal relations between cognitions, emotions, and behaviour of the child. The training is designed to reduce aggressive behaviour in highly aggressive children at elementary schools. The long term goal is to prevent the development of disruptive behaviour disorders. Trainers worked individually, in 8 weekly sessions of 45 minutes, with the target child. Children were seen during the school day from January until March. The trainer met with parents and teachers before the start of the training, during a mid term evaluation, and at the end of the training.

The training consisted of two phases. In the first phase, trainers investigated child's specific needs and competences. The first session starts with a general introduction, which is the same for all children. Next, trainers were able to choose two from six exercises that were best suited for the individual child, for the second and third session. After the third session, an individual analysis of child's competences was made and discussed with parents and teachers during a midterm evaluation, resulting in an individual intervention plan. For the intervention plan trainers chose five from nine program components that were most appropriate for the individual child's needs, as described in the trainer manual. Before phase 2 (session 4-8) started, a contract between the trainer and child was signed, in which the training program is described. Exercises focused on: 1) self-perception (less negative, realistic self-perception); 2) social cognitions (attribution of benign intent in ambiguous situations, accurate representation of other children emotions); 3) anger management (emotion-regulations strategies, e.g. "stopthink-act"); and 4) aggressive behaviour (generation of less aggressive responses to social provocations). Parents and teachers received information after each training session about what was done during the training. Also, they were asked to practise together with the child his or her newly learned skills. ${ }^{1}$

\footnotetext{
${ }^{1}$ More detailed description of the intervention can be obtained from the first author.
} 


\section{Treatment fidelity}

In this study, an existing frequently used implemented intervention is evaluated and participating Stay Cool Kids trainers from youth mental health care centres $(n=33)$ are typical providers of the intervention within these schools. Trainers have a background in clinical child psychology, and have to be certified as a Stay Cool Kids trainer. To become certified, trainers have to run three pilot training sessions, under supervision from accredited Stay Cool Kids trainers. These initial pilot training was prior to implementing the program, and these trained children were not included in the study. During the intervention period for this study trainers had two-weekly meetings to discuss training and get feedback from other trainers and supervisors. Trainers filled in logs after every intervention session. Logs completed by the trainers indicated that $99 \%$ of the training sessions were completed as planned. The average training session lasted 45 minutes. Trainers changed the content of their training session in $6.5 \%$ of the cases, when the planned training session did not work for the specific child. Overall, it was found that Stay Cool Kids was conducted as intended.

\section{Parents and teachers satisfaction with program}

Parents and teachers in the intervention condition were asked to fill in a short questionnaire at Time 2 to assess the level of satisfaction with the program. Overall, parents and teachers were satisfied with the program at post test (scale 0-6; $M_{\text {teachers }}=4.4(1.24), M_{\text {mothers }}=4.6(1.35)$, $M_{\text {fathers }}=4.6(1.18)$ ).

\section{Measures}

Child aggressive behaviour. Reactive and proactive aggression according to teachers were measured with the Teacher Rating of Aggression (TRA; Dodge and Coie, 1987; Dutch version; Hendrickx, Crombez, Roeyers and de Castro, 2003). Items for both reactive aggression (e.g. "When this child has been teased or threatened, he or she gets angry easily and strikes back"; 3 items) and proactive aggression (e.g. "This child uses force to dominate peers"; 3 items) were rated on a 5 -point scale $(1=$ never to $5=$ always). Parents and children also reported on the child's reactive and proactive aggression, with adapted parent and child versions of the TRA (Dodge and Coie, 1987; Hendrickx et al., 2003). Cronbach's alphas were as follows. For teachers: reactive $\mathrm{T} 1=.84, \mathrm{~T} 2=.86$; proactive $\mathrm{T} 1=.79, \mathrm{~T} 2=.88$; children: reactive $\mathrm{T} 1=.53, \mathrm{~T} 2=.58$; proactive $\mathrm{T} 1=.70, \mathrm{~T} 2=.75$; mothers: reactive $\mathrm{T} 1=.72, \mathrm{~T} 2=.80$; proactive $\mathrm{T} 1=.77, \mathrm{~T} 2=.76$; and fathers: reactive $\mathrm{T} 1=.74, \mathrm{~T} 2=.77$; proactive $\mathrm{T} 1=80, \mathrm{~T} 2=.78$.

As a screening measure the Externalizing subscale of the Teacher Report Form (age 618, Achenbach, 1991; Verhulst, van der Ende and Koot, 1997) was used. To determine if the mean level of externalizing behaviour for children in the intervention condition was still in the clinical range after the intervention, we also included the broad band externalizing scale of the TRF as outcome measure (32 items; T1 $\alpha=.85, \mathrm{~T} 2 \alpha=.84$ ).

Self perception. To assess self perception, children were asked to fill in the subscale "Behaviour attitude" of the Dutch version of the Self Perceived Competence Scale for Children (Harter, 1982; Veerman, Straathof, Treffers, van den Bergh and Ten Brink, 1997) (e.g. "Some kids usually get in trouble because of the things they do - other kids don't do 
things that get them into trouble"). Children first had to decide which of the items in the pair better described them, and then they had to choose between "sort of true" or "really true". With this format the effects of a pull for social desirability are reduced (T1 $\alpha=.68, \mathrm{~T} 2 \alpha=.73)$.

Hostile intent attribution. Four hypothetical stories were presented to children (Social Information Processing test, de Castro et al., 2005). The stories all concerned being hindered by a peer whose intentions are ambiguous (e.g. "Imagine: You and a friend are taking turns at a game at the pin-ball machine. When one has lost the game, it is the other's turn. Now it's your turn, and you are doing great. You will soon earn an extra ball, so you are trying very hard! The boy you are playing with watches the game over your shoulder. He looks into the pin-ball machine to see where the ball is. Then he shouts 'Watch out! The ball will drop from the right side!' But all of the sudden the ball appears from the left side and now you have lost the game!"). Immediately after hearing a story the child was asked to indicate why the peer in the story might have acted the way he or she did. Responses were written down by the interviewer and scored as 0 (benign intent) or 1 (hostile intent). Mean kappa was calculated to measure intercoder agreement, which was .95 to 1.00. Disagreements were resolved through discussions until consensus was reached. An open-answer hostile attribution variable was created by counting the number of stories with hostile answers $(0=$ never a hostile attribution to $4=$ always a hostile attribution). Furthermore, the child was asked to indicate the peer's intent on a 10-point rating-scale ranging from $1=$ to be "nice" to $10=$ to be "mean". Scores were averaged over the four stories. Because the open-answer and rating-scale variables were strongly correlated $(r=.74)$, they were combined by standardizing each variable and then computing their average (Cronbach's alpha $\mathrm{T} 1=.64, \mathrm{~T} 2=.62$ ).

Response generation. Next, children were asked what they would do if the events in the vignette would actually happen to them. Responses were written down by the interviewer and scored 0 (not aggressive), 1 (verbally aggressive or coercive response), 2 (physically aggressive response), and scores were averaged over the vignettes. In a previous study (de Castro et al., 2005) findings showed that an accurate interval scale of response aggressiveness could be created by weighting physical aggression with two points, verbal aggression with 1 point, and non-aggression with zero points. Inter-rater's agreement was found to be high: 95\%. Cronbach's alphas were .65 at $\mathrm{T} 1$ and .62 at $\mathrm{T} 2$.

Response evaluation. Next, a possible behavioural response to the problem was presented (e.g. "if this happens to me, I will hit the child who pushed me"), to measure Approval of Aggression. This was measured with a 10-point scale where the child had to indicate whether he or she thought this was a good response $(0=$ not a good response to $10=$ a good response $)$. Ratings were averaged over the stories (Cronbach's alpha $\mathrm{T} 1=.66, \mathrm{~T} 2=.66$ ). Enactment of Aggression was also measured. Children similarly had to indicate on a 10-point scale to what extent they would enact a presented aggressive response themselves. Cronbach's alphas were .76 at $\mathrm{T} 1$, and .66 at $\mathrm{T} 2$.

\section{Data-analyses}

First, we tested for possible differences at baseline scores between the intervention and control group. Next, intervention effects were examined using a series of analyses of covariance (ANCOVA) on the post test scores on reactive aggression, proactive aggression, 
social cognitions, and self-perception, using the pre test scores as covariate and condition status $(0=$ control group; $1=$ intervention group) as a fixed factor. Adjusting for pretest scores in ANCOVAs is recommended for testing intervention effects (Rausch, Maxwell and Kelly, 2003). To test for moderating effects of gender and ethnicity, we conducted additional ANCOVAs in which gender $(0=$ boys; $1=$ girls $)$ or ethnicity $(0=$ native Dutch; $1=$ Immigrant) were added as fixed factors, and interactions with condition status were tested.

Effect sizes were calculated as the standardized mean difference, with mean gain scores. The adjusted posttest mean (posttest mean minus baseline mean) of the control group was subtracted from the adjusted posttest mean of the intervention group, and the results were divided by the pooled standard deviation (Lipsey and Wilson, 2001). Effect sizes were coded such that positive values mean a positive outcome for the experimental group, compared to the control group. An effect size of .20 was considered small, .50 was considered medium, and an effect size of .80 was considered large (Cohen, 1988).

Next, we examined whether the level of externalizing behaviour of children declined to a subclinical or normal range for more intervention than control children, using the norms of the Teacher Report Form (TRF). We calculated the percentage of children in the normal, subclinical, and clinical range at pre- and post test and compared this between intervention and control group with chi-square tests.

\section{Results}

\section{Preliminary analyses}

Before running the analyses, the normality in the distribution of variables was assessed. Absolute values of skewness (skew) $>2$, and absolute values of kurtosis (kurt) $>1$ represent deviations from normal distributions (Muthén and Kaplan, 1992). Mother reported proactive aggression at post test $($ skew $=1.84$, kurt $=5.10)$, and child reported proactive aggression $(\mathrm{T} 1$ skew $=1.95$, kurt $=4.18 ; \mathrm{T} 2$ skew $=2.07$; kurt $=5.37)$, response generation $(\mathrm{T} 1$ skew $=2.06$, kurt $=4.31 ; \mathrm{T} 2$ skew $=2.25$; kurt $=5.19)$, approval of aggression $(\mathrm{T} 1$ skew $=1.86$, kurt $=2.99 ; \mathrm{T} 2$ skew $=1.98 ;$ kurt $=3.78)$, and enactment of aggression $(\mathrm{T} 2$ skew $=1.73$, kurt $=2.57$ ) appeared to be somewhat skewed. Log transformations were performed for these scales, and after transformation scales were normally distributed. Correlations among variables measured at pretest are presented in Table 2.

Although transformed scores were used in the analyses, Table 3 shows, for ease of interpretation, non transformed means and standard deviations for the intervention and control group on outcome measures at pre and post treatment, as well as effect sizes. Children in the intervention and control group differed only on teacher reported proactive aggression at pre test, with higher levels of proactive aggression for children in the intervention condition $(t=2.26, p=.03)$. There were no differences on outcome behaviour for boys and girls. Native Dutch and immigrant children differed only on teacher reported reactive aggression at pretest, with higher levels of reactive aggression for immigrant children $(t=3.35, p=.00)$

\section{Intervention effects}

Reactive and proactive aggression. For child reported reactive aggression, the ANCOVA revealed a significant condition effect $(F(2,263)=4.06, p=.02)$, indicating that Stay 
Table 2. Intercorrelations among assessed variables at pretest

\begin{tabular}{|c|c|c|c|c|c|c|c|c|c|c|c|c|c|}
\hline Outcome & 1. & 2. & 3. & 4. & 5. & 6. & 7. & 8. & 9. & 10. & 11. & 12. & 13. \\
\hline \multicolumn{14}{|l|}{ Reactive aggression } \\
\hline Child & - & & & & & & & & & & & & \\
\hline Teacher & $.19^{* *}$ & - & & & & & & & & & & & \\
\hline Mother & $.14^{*}$ & .10 & - & & & & & & & & & & \\
\hline Father & .05 & .07 & $.72^{* *}$ & - & & & & & & & & & \\
\hline \multicolumn{14}{|l|}{ Proactive aggression } \\
\hline Child & $.42^{* *}$ & .05 & $.19^{* *}$ & .06 & - & & & & & & & & \\
\hline Teacher & $.19^{* *}$ & $.45^{* *}$ & .01 & -.02 & $.16^{*}$ & - & & & & & & & \\
\hline Mother & $.16^{*}$ & .04 & $.54^{* *}$ & $.41^{* *}$ & $.14^{*}$ & .11 & - & & & & & & \\
\hline Father & .09 & .00 & $.48^{* *}$ & $.54^{* *}$ & .09 & .12 & $.74^{* *}$ & - & & & & & \\
\hline Self-perception & $-.26^{* *}$ & -.07 & $-.15^{*}$ & $-.12^{*}$ & $-.31^{* *}$ & $-.24^{* *}$ & -.10 & -.09 & - & & & & \\
\hline Hostile intent & $.25^{* *}$ & .08 & .09 & .03 & $.22^{* *}$ & $.16^{*}$ & .03 & .07 & $-.14^{*}$ & - & & & \\
\hline Response generation & $.43^{* *}$ & .12 & .13 & .06 & $.49^{* *}$ & .08 & .12 & .10 & $-.22^{* *}$ & $.34^{* *}$ & - & & \\
\hline Approval aggression & $.38^{* *}$ & .09 & .07 & .02 & $.45^{* *}$ & .08 & .07 & .10 & $-.24^{* *}$ & $.19^{* *}$ & $.50^{* *}$ & - & \\
\hline Enactment aggression & $.42^{* *}$ & 07 & .08 & .01 & $.49^{* *}$ & .10 & .15 & .11 & $-.24^{* *}$ & $.20^{* *}$ & $.55^{* *}$ & $.75^{* *}$ & - \\
\hline
\end{tabular}

Note. ${ }^{*} p<.05,{ }^{* *} p<.01$ 
Table 3. Means, standard deviations and effect sizes for outcome variables

\begin{tabular}{|c|c|c|c|c|c|}
\hline \multirow[b]{2}{*}{ Outcomes } & \multicolumn{2}{|c|}{ Intervention } & \multicolumn{2}{|c|}{ Control } & \multirow[b]{2}{*}{$\begin{array}{l}\text { Effect } \\
\text { Size }\end{array}$} \\
\hline & $\begin{array}{c}\text { Pre } \\
M(S D)\end{array}$ & $\begin{array}{l}\text { Post } \\
M(S D)\end{array}$ & $\begin{array}{c}\text { Pre } \\
M(S D)\end{array}$ & $\begin{array}{c}\text { Post } \\
M(S D)\end{array}$ & \\
\hline \multicolumn{6}{|l|}{ Reactive aggression } \\
\hline Child & $3.03(.88)$ & $2.80(.81)$ & $3.03(.81)$ & $3.00(.87)$ & .21 \\
\hline Teacher & $3.84(.87)$ & $3.40(.89)$ & $3.74(.95)$ & $3.57(.94)$ & .28 \\
\hline Mother & $3.04(.82)$ & $2.68(.79)$ & $2.93(.79)$ & $2.82(.72)$ & .32 \\
\hline Father & $2.73(.76)$ & $2.73(.75)$ & $2.60(.68)$ & $2.68(.65)$ & .11 \\
\hline \multicolumn{6}{|l|}{ Proactive aggression } \\
\hline Child & $1.48(.70)$ & $1.35(.54)$ & $1.61(.80)$ & $1.62(.84)$ & .22 \\
\hline Teacher & $2.46(.89)$ & $2.09(.98)$ & $2.17(.89)$ & $2.08(.92)$ & .30 \\
\hline Mother & $1.61(.62)$ & $1.41(.47)$ & $1.62(.66)$ & $1.52(.48)$ & .18 \\
\hline Father & $1.49(.51)$ & $1.40(.48)$ & $1.49(.51)$ & $1.55(.49)$ & .30 \\
\hline \multicolumn{6}{|l|}{ Social cognitions } \\
\hline Self-perception & $2.54(.55)$ & $2.87(.54)$ & $2.53(.56)$ & $2.59(.59)$ & .49 \\
\hline Hostile intent $^{1}$ & $.17(.69)$ & $.15(.48)$ & $-.07(.57)$ & $.14(.49)$ & .15 \\
\hline Response generation & $.25(.41)$ & $.21(.41)$ & $.31(.53)$ & $.26(.44)$ & .00 \\
\hline Approval aggression & $2.36(1.88)$ & $1.95(1.50)$ & $2.56(2.51)$ & $2.47(2.32)$ & .22 \\
\hline Enactment aggression & $2.69(2.06)$ & $2.18(1.75)$ & $2.59(2.15)$ & $2.53(2.21)$ & .17 \\
\hline
\end{tabular}

Note: ${ }^{1}$ Standardized scores

Cool Kids decreased reactive aggression at post test. Moreover, the intervention had a significant effect on child reported proactive aggression $(F(2,263)=8.02, p=.02)$. For teacher reported reactive aggression, effects were significant $(F(2,263)=3.81, p=.05)$. No significant intervention effect was found for teacher reported proactive aggression. Significant intervention effects were found for mother reported reactive $(F(2,263)=10.71, p<.001)$ and proactive aggression $(F(2,263)=.3 .81, p=.05)$, indicating that children showed less reactive and proactive aggression after the intervention compared to children in the control condition. For father reported reactive aggression, condition did not predict scores at post test. However, the intervention had a significant effect for father reported proactive aggression $(F(2,263)=6.02, p=.02)$. Intervention children showed lower levels of proactive aggression at post test in intervention group compared to control group.

Social cognitions and self-perception. Children who received the Stay Cool Kids intervention reported higher levels of self-perception at posttest compared to children in the control condition $(F(2,263)=17.37 ; p<.001)$. The intervention also had a significant effect on level of approval of aggression at post test, indicating that the intervention reduced approval of aggression $(F(2,263)=4.69, p=.04)$. For hostile intent attribution, response generation and enactment of aggression, there were no significant intervention effects.

\section{Moderator analyses}

To test whether gender and ethnicity moderated intervention effects, we added gender and ethnicity (separately) in ANCOVA models, and tested the gender $\times$ condition and 
ethnicity $\times$ condition interactions. For child reported proactive aggression a significant gender $\times$ condition interaction effect was found $(F(3,263)=8.02, p=.02)$. Post hoc analyses revealed that the intervention effects were stronger for boys $(d=.55)$ than for girls $(d=.23)$.

For teacher reported reactive aggression a significant ethnicity $\mathrm{x}$ condition interaction was found $(F(3,263)=7.89, p=.01)$. Post hoc analyses showed stronger intervention effects for immigrant children $(d=.87)$ than for native Dutch children $(d=.06)$.

Also for child response generation, a marginally significant ethnicity $\mathrm{x}$ condition interaction was found $(F(3,263)=4.14 ; p=.05)$. Post hoc analyses showed that intervention effects on aggressive response generation were stronger for children with an immigrant background $(d=.58)$ than for native Dutch children $(d=.15)$.

\section{Recovery}

(Sub) clinical externalizing behaviour problems. Children were selected by their teachers, based on their subclinical and clinical levels of externalizing behaviour. At pretest, teachers reported child externalizing behaviour of the children in the intervention group in the clinical range for $61 \%$ of the children and in the subclinical range for $39 \%$. For the control group, $67 \%$ was rated as clinical, and $33 \%$ as subclinical. These small differences between groups were not significant $\left(\chi^{2}(1, n=264)=.98, p=.61\right)$. However, at post test, for the intervention group, teachers reported child externalizing behaviour for $26 \%$ in the normal range, for $22 \%$ in the subclinical range, and for $52 \%$ in the clinical range. For the control group, teachers reported child externalizing behaviour for $19 \%$ in the normal range, for $11 \%$ in the subclinical range, and for $70 \%$ in the clinical range. These differences in percentages between conditions were significant $\left(\chi^{2}(2, n=264)=5.89, p=.01\right)$, indicating that the intervention significantly increased recovery according to teacher ratings.

\section{Discussion}

In the present study, we examined whether the routine practice of the Stay Cool Kids intervention was effective in reducing reactive and proactive aggression and enhancing social cognitions and self-perception. In addition, through moderator analyses, we examined ethnic and gender differences in response to the intervention. Overall, Stay Cool Kids significantly reduced aggressive behaviour according to children, mothers, fathers and teachers, and clinical externalizing behaviour problems according to teachers. Children showed more positive levels of self-perception and reported lower approval of aggression.

These results demonstrate that the intervention can reduce the level of aggression, across informants, in children at risk of developing more serious behaviour problems, and therefore may help prevent children from having various negative outcomes later in life. Effect sizes on aggressive behaviour for teachers and children ranged from .21 to .30 . For father and mother reported aggression, there was a larger variability in effect sizes ranging from .11 to .32 . The effect sizes can be considered as small to modest effects. However, even small effect sizes can be of practical significance, because a small reduction in aggressive behaviour may break a vicious cycle. Therefore, it is important to neither exaggerate nor minimize both the theoretical and practical significance of small to modest effect sizes (McCartney and Rosenthal, 2000). A notable finding was that fathers reported a significant decrease in 
proactive aggression, but not in reactive aggression. Reactive aggression might be observable less early in the home setting, since there are less conflict situations with peers. In general, fathers spend less time with their children than mothers (Jones, Forehand and Beach, 2000) and therefore may have less opportunity to see their child in situations with peers. For teachers, we found the opposite. There was a significant intervention effect on reactive aggression, but not on proactive aggression. Reactive aggression may be more prominent in the school situation, as reaction on provocation by peers.

Effect sizes found in the current study are comparable to mean effect sizes found in metaanalyses on cognitive behavioural interventions for aggressive children $(\mathrm{ES}=.26$; Wilson and Lipsey, 2006) and on selected school-based interventions (ES =.29; Wilson and Lipsey, 2007). It is noteworthy that most intervention studies are demonstration or research programs that usually result in larger effects sizes (Kratochwill and Shernoff, 2004). Findings of this study show comparable effect sizes, but these effects were found under routine-practice conditions.

Regarding child self-perception and social cognitions, we found that children were more positive about their own behaviour after the intervention, and that they were less likely to evaluate an aggressive response as a good way to obtain desired outcomes. This indicates that the Stay Cool Kids intervention can have some impact on problems in social cognitive functioning. However, although we found significant effects on two social cognitive outcomes, several other aspects of the social cognitive processes did not change as a result of the intervention. It is possible that these aspects (e.g. hostile intent and enactment of aggression) are less sensitive to change and that more time is needed to internalize the newly learned cognitions. Changes in approval of aggression and perception of selves might well result in benign schemata that, in turn, can change social information processes (Lochman and Wells, $2002 \mathrm{~b}$ ). The present study was unable to test whether changes in self-perception and approval of aggression caused the reduction in child aggressive behaviour. Longitudinal data with more time points are needed to test for mediational processes.

How do present results compare to results obtained with similar interventions? The Coping Power Program is a social-cognitive school-based group and parent intervention designed to reduce conduct problems. The intervention is effective in reducing aggression and disruptive classroom behaviour and improving self-esteem in boys. However, teachers did not report effects (Lochman, Burch, Curry and Lampron, 1984). Lochman and colleagues state that behavioural changes were modest and apparently situation-specific. Results of the current study show that the Stay Cool Kids intervention has the potential to reduce aggression (although effects are modest in size) across situations, which might be a result of the individual, tailor-made format. Another comparable, although multisite, intervention focusing on a high-risk sample is the Fast Track intervention (McMahon et al., 1999; Slough, McMahon and CPPRG, 2008). Effects were found on emotional and social coping skills and on observed rates of problem behaviour at school. Teachers and parents did not report significant improvements in child behaviour. The authors state that major reductions in aggressivedisruptive behaviour are needed in high-risk children before losing their "status" as disruptive by teachers (McMahon et al., 1999). As in the current study, parents did not select children for the Fast Track intervention, which might explain why parents did not report reductions in aggressive behaviour in the Fast Track trial. In the current study, parents and teachers do report (modest) effects of the training, which strengthens our conclusion that the training may have some impact on child behaviour in different situations. 
To examine whether subgroups of children benefited more from the intervention, moderator analyses were performed. We found that gender and ethnicity moderated some of the intervention effects. Effects on teacher reported reactive aggression were stronger for children with an immigrant background than for native Dutch children. Initial levels of reactive aggression according to teachers were higher for immigrant children, which is in line with findings in other studies on mental health in immigrant (Moroccan) children in the Netherlands (Stevens and Vollebergh, 2008). Therefore, perhaps there was more room for improvement (Wilson and Lipsey, 2007). Immigrant children showed also a stronger decrease in aggressive response generation compared to native Dutch children. Because Stay Cool Kids is an individualized intervention, trainers perhaps focused more on this specific social cognitive aspect for immigrant children, and therefore they learned to generate less aggressive responses in social situations. The increasing diversity of the Dutch population requires an intervention that is sensitive and effective for ethnically diverse children. Most evidencebased interventions are designed for majority children, and adapted afterwards to specific needs of minority children (Yasui and Dishion, 2007). In the Stay Cool Kids intervention, the content of the training is based on an individual competence analysis, in which the child's individual needs are investigated. Because of this, there is flexibility to address specific preferences and needs of specific ethnic groups. Gender emerged as moderator only for child reported proactive aggression, with stronger effects for boys. It has been speculated that gender differences in response to intervention can occur as a consequence of differing therapy preferences of boys and girls (Garber, 2006). There were no other moderating effects of gender. Therefore, we can conclude that the Stay Cool Kids intervention can be effective in reducing aggressive behaviour as well in at-risk boys as in girls. This enriches our knowledge about effectiveness of interventions for girls, since gender differences were less clear as a result of overrepresentation of boys in study samples (Brestan and Eyberg, 1998).

Another way to evaluate the effects of a program is to examine to what extent changes are clinically relevant (Kendall, 1999). Therefore, we examined in this study whether child's elevated level of externalizing behaviour, which was the selection criterion of this study, changed significantly as a result of the intervention. We found clinically relevant changes, reported by teachers. Externalizing behaviour of children who received the Stay Cool Kids intervention was rated more frequently in the normal or subclinical range, compared to children in the control condition. For children in the control condition, the externalizing behaviour was most frequently rated in the clinical range. This indicates that the intervention can, at least for part of the participating children, reduce clinical levels of externalizing behaviour to subclinical or normal levels.

Although many school-based interventions have shown significant initial effects on child's aggressive behaviour, findings on long-term effects are mixed. For some studies positive shortterm effects maintained or emerged at follow-up (e.g. Conduct Problems Prevention Research Group, 2002; Scott, 2005), whereas for other studies effects faded with time (August et al., 2004; Tolan and Gorman-Smith, 2002). In the current study we did find posttest intervention effects; however, it is important to test whether the Stay Cool Kids training may also set the stage for improvement of behaviour in middle and high school years. Longitudinal data are needed to detect impact of the intervention in the long term, so called "sleeper-effects", and the developmental processes over time.

There are several limitations to this study that may have affected effect sizes and should be addressed in future research. First, it should be noted that the unit of analyses (individual 
level) did not match the unit of randomization (school level), which might have increased the risk of false-positive finding (Stice, Shaw, Bohon, Marti and Rohde, 2009). The present design permitted us to study actual effects of an intervention implemented in routine school practice. Allowing each school to participate both in control and intervention conditions and blockwise randomization made it practically feasible for schools to participate. This would not have been possible with a traditional individual randomization to either control or intervention condition, because ethical issues concerning assignment of individual children in the same classroom to different conditions and lack of motivation to participate in the control condition would have prevented schools, teachers and parents from participating in the study. Moreover, the present design prevented biases due to school factors by delivering intervention and control conditions in the same schools.

Second, intervention effects are based on child, parent and teacher reported data, and informants were not blind to the condition. Although there are problems inherent in ratings of parents and teachers, especially when they are involved in some way in the intervention, the fact that intervention effects were found across all informants and that the pattern of findings was similar across informants lends credibility to the findings. It is important to note that teachers and parents did not conduct the intervention themselves, as is frequently the case in other intervention studies. Therefore, they still may be critical to changes in child's behaviour. However, for future studies we suggest a multi-method strategy; including observational measures would increase reliability and generalizibility of results (e.g., Shores et al., 1993). Observational data have been shown to be resistant to biases originating in observed persons (e.g. when the child attempts to fake good behaviour) or in trained coders (i.e. no self-fulfilling expectations of behaviour). However, observational data have some limitations too. Observers tend to gather data during limited time intervals and have less access to the diversity of behaviour settings found in schools (Ladd and Profilet, 1996). Therefore, data tend to be based on restricted samples of behaviour. Furthermore, aggressive behaviour often happens with peers, not in the presence of adults (e.g. Dodge and Coie, 1987). Peer ratings, in addition to self-, teacher- and parent-reports, might provide useful information. Using a multi-method strategy in intervention studies, which includes observational measures and peer ratings in addition to questionnaires (e.g. Lochman and Wells, 2002b), would result in the most comprehensive picture of changes in child behaviour. Many intervention studies, however, share this limitation of relying on questionnaires (e.g. Domitrovich, Cortes and Greenberg, 2007). These studies still made great efforts to include empirical estimates that take into consideration recent recommendations (combine reports from different informants, use broad-assessment with information from adults having different relationships with the child) to use comprehensive, reliable and valid measurements (Grietens et al., 2004).

It is also worth noting that children were selected for this intervention by their teachers because of elevated levels of externalizing behaviour at schools. Selecting children for the intervention based on a combination of informants (teachers, parents and possibly peers) on the child's externalizing behaviour might lead to larger effect sizes, as a result of more involvement in the intervention. Moreover, the control group in this study did not receive any treatment. It is possible that the beneficial effects of Stay Cool Kids are simply the consequence of receiving attention and that some other treatment would have the same effect.

Fourth, the intervention is conducted by trained professionals rather than by school personnel. Although there are several advantages from using trained professionals, it has been found that interventions provided by staff that is working full-time in school (for 
example teachers) are delivered with greater intensity, are operated more frequently, used more regularly, and are offered to more students. But to realize this a large portion of the regular job of teachers should be dedicated to the intervention activity (Gottfredson and Gottfredson, 2002). Implementation may be more guaranteed when working with trained professionals (Silvia and Thorne, 1997).

Finally, with the research design used in the current study, twice as many intervention students as control students participated. The reason for this is that we plan to examine the effects of a booster intervention for part of the intervention group. However, this is beyond the scope of the current study. Including more intervention students than control students does not inflate the effect sizes in this study. In a meta-analysis (Stice et al., 2009) it has been found that design factors, such as randomization at school level, are not related to the magnitude of effect sizes.

Despite these limitations, the results of this study are encouraging. The individualized preventive intervention, Stay Cool Kids, delivered to children at-risk for externalizing behaviour problems can have some impact on reactive and proactive aggression, some aspects of social cognitive functioning, and self-perception. Based on the high treatment completion rate $(99 \%)$, treatment integrity and high level of satisfaction with the training, it can be concluded that this program is an example of how prevention activities can be successful using the school as location. Moreover, this study showed that the program is particularly effective for children with an immigrant background and it proved to be effective for girls as well. The current study fills a gap in the literature because it evaluated the effects of an already existing real-world program, which is delivered in a one-to-one setting in schools and is tailormade. We were able to show that Stay Cool Kids children showed clinically relevant changes in teacher-reported aggressive behaviour. The intervention can move externalizing problem behaviour into a normative range, which strengthens implications for clinical practice. This study meets several of the standards for evidence developed by the Society for Prevention Research regarding efficacy, effectiveness and dissemination (Flay et al., 2005).

These results provide information to clinicians working in schools with children showing elevated levels of externalizing behaviours and to policymakers concerning options for how to prevent the development of later, more serious, externalizing behaviour problems in at-risk youth at elementary schools. Effectiveness under real-world conditions, across informants, and on diverse outcomes, is demonstrated.

\section{References}

Achenbach, T. M. (1991). Manual for the Teacher Report Form and 1991 Profiles. Burlington: University of Vermont, Department of Psychiatry.

Achenbach, T. M., McConaughy, S. and Howell, C. T. (1987). Child/adolescent behavioural and emotional problems: implications of cross-informant correlations for situational specificity. Psychological Bulletin, 87, 213-232. doi:10.1037/0033-2909.101.2.213

August, G. J., Lee, S. S., Bloomquist, M. L., Realmuto, G. M. and Hektner, J. M. (2004). Maintenance effects of an evidence-based prevention innovation for aggressive children living in culturally diverse urban neighborhoods. The Early Risers effectiveness study. Journal of Emotional and Behavioural Disorders, 12, 194-205. doi:10.1177/10634266040120040101

Bandura, A. (1973). Aggression: a social learning approach. Englewood Cliffs: Prentice Hall. 
Baranowski, T., Cullen, K., Nicklas, T., Thompson, D. and Baranowski, J. (2002). School-based obesity prevention: a blueprint for taming the epidemic. American Journal of Health Behaviour, 26, 486-493.

Baraldi, A. N. and Enders, C. K. (2010). An introduction to modern missing data analyses. Journal of School Psychology, 48, 5-37. doi:10.1016/j.jsp.2009.10.001

Brestan, E. V. and Eyberg, S. M. (1998). Effective psychosocial treatments of conduct-disordered children and adolescents: 29 years, 82 studies, and 5,7272 kids. Journal of Clinical Child Psychology, 27, 180-189. doi:10.1234/12345678

Broidy, L. M., Nagin, D. S., Tremblay, R. E., Bates, J. E., Brame, B., Dodge, K. A., et al. (2003). Developmental trajectories of childhood disruptive behaviours and adolescent delinquency: a six-site, cross-national study. Developmental Psychology, 39, 222-245. doi:10.1037/0012-1649.39. 2.222

Buckley, J. A. (2009). Introduction to this special issue: implementing evidence-based interventions in elementary schools for students with and at risk for severe behaviour disorders. Journal of Emotional and Behavioural Disorders, 17, 195-196. doi:10.1177/1063426609345866

Bushman, B. J., Baumeister, R. F., Thomaes, S., Ryu, E., Begeer, S. and West, S. G. (2009). Looking again, and harder, for a link between low self-esteem and aggression. Journal of Personality, 77, 427446.

Campbell, S. B., Spieker, S., Burchinal, M. and Poe, M. D. (2006). Trajectories of aggression from toddlerhood to age 9 predict academic and social functioning through age 12. Journal of Child Psychology and Psychiatry, 47, 791-800. doi:10.1111/j.1469-7610.2006.01636.x

Catron, T. and Weiss, B. (1994). The Vanderbilt School-Based Counselling Program. Journal of Emotional and Behavioural Disorders, 2, 247-253. doi:10.1177/ 106342669400200407

Cohen, J. (1988). Statistical Power Analysis for the Behavioural Sciences. Hillsdale, NJ: Erlbaum.

Cowen, E. L., Hightower, A. D., Pedro-Carroll, J. L., Work, W. C., Wyman, P. A. and Haffey, W. G. (1996). School Based Prevention for Children at Risk: the primary mental health project. Washington, DC: American Psychological Association.

Crick, N. R. and Dodge, K. A. (1994). A review and reformulation of social information-processing mechanisms in children's social adjustment. Psychological Bulletin, 115, 74-101. doi:10.1037/00332909.115.1.74

Crick, N. R. and Grotpeter, J. K. (1995). Relational aggression, gender, and social-psychological adjustment. Child Development, 66, 710-722. doi:10.2307/1131945

De Castro, B. O., Brendgen, M., van Boxtel, H., Vitaro, F. and Schaepers, L. (2007). Accept me or else: disputed overestimation of social competence predicts increases in proactive aggression. Journal of Abnormal Child Psychology, 35, 1573-2835. doi:10.1007/s10802-006-9063-6

De Castro, B. O., Merk, W., Koops, W., Veerman, J. W. and Bosch, J. D. (2005). Emotions in social information processing and their relations with reactive and proactive aggression in referred aggressive boys. Journal of Clinical Child and Adolescent Psychology, 34, 105-116. doi:10.1207/s15374424jccp3401_10

De Castro, B. O., Veerman, J. W., Koops, W., Bosch, J. D. and Monshouwer, H. J. (2002). Hostile attribution of intent and aggressive behaviour: a meta-analysis. Child Development, 73, 916-934. doi:10.1111/1467-8624.00447

Dishion, T. J., McCord, J. and Poulin, F. (1999). When interventions harm: peer groups and problem behaviour. American Psychologist, 54, 755-764. doi:10.1037//0003-066X.54.9.755

Dishion, T. J. and Patterson, G. R. (2006). The development and ecology of antisocial behaviour in children and adolescents. In D. J. Cohen and D. Cicchetti (Eds.), Developmental Psychopathology (pp. 503-541). Hoboken, NJ: Wiley.

Dodge, K. A. (1986). A social information processing model of social competence in children. In M. Perlmutter (Ed.), The Minnesota Symposium on Child Psychology (Vol. 18, pp. 77-125). Hillsdale, NJ: Lawrence Erlbaum. 
Dodge, K. A. (1991). The structure and function of reactive and proactive aggression. In D. Pepler and K. H. Rubin (Eds.), The Development and Treatment of Childhood Aggression (pp. 201-218). Hillsdale, NJ: Lawrence Erlbaum Associates, Inc.

Dodge, K. A. and Coie, J. D. (1987). Social information processing factors in reactive and proactive aggression in children's peer groups. Journal of Personality and Social Psychology, 53, 1146-1158. doi:10.1037/0022-3514.53.6.1146

Domitrovich, C. E., Cortes, R. C. and Greenberg, M. T. (2007). Improving young children's social and emotional competence: a randomized trial of the preschool "PATHS" curriculum. The Journal of Primary Prevention, 28, 67-91. doi:10.1007/s10935-007-0081-0

Donnellan, M. B., Trzesniewski, K. H., Robins, R. W., Moffitt, T. E. and Caspi, A. (2005). Low self-esteem is related to aggression, antisocial behaviour, and delinquency. Psychological Science, $16,328-335$.

Eichelsheim, V., Buist, K., Deković, M., Wissink, I., Frijns, T., van Lier, P., et al. (2009). Associations among the parent-adolescent relationship, aggression and delinquency in different ethnic groups: a replication across two Dutch samples. Social Psychiatry and Psychiatric Epidemiology, 44, 1-8. doi:10.1007/s00127-009-0071-z

Evans, S. W., Langberg, J. and Williams, J. (2003). Achieving generalization in school-based mental health. In M. D. Weist, S. W. Evans and N. A. Lever (Eds.), Handbook of School Mental Health: advancing practice and research (pp. 335-348). New York: Kluwer Academic/Plenum Publishers.

Flay, B. R., Biglan, A., Boruch, R. F., Gonzales Castro, F., Gottfredson, D., Kellam, S., et al. (2005). Standards of evidence: criteria for efficacy, effectiveness and dissemination. Prevention Science, 124. doi:10.1007/s11121-005-5553-y

Frick, P. J. (2000). A comprehensive and individualized treatment approach for children and adolescents with conduct disorders. Cognitive and Behavioural Practice, 7, 30-37. doi:10.1016/S10777229(00)80005-X

Garber, J. (2006). Depression in children and adolescents: linking risk research and prevention. American Journal of Prevention Medicine, 31(6 Suppl 1), S104-S125. doi: 10.1016/j.amepre.2006.07.007

Gottfredson, D. C. and Gottfredson, G. D. (2002). Quality of school-based prevention programs: results from a national survey. Journal of Research in Crime and Delinquency, 39, 3-35. doi: $10.1177 / 002242780203900101$

Gottfredson, D. C. and Wilson, D. B. (2003). Characteristics of effective school-based substance abuse prevention. Prevention Science, 4, 27-38. doi:10.1023/A:1021782710278

Greenberg, M. T., Kusche, C. A., Cook, E. T. and Quamma, J. P. (1995). Promoting emotional competence in school-aged children: the effects of the PATHS curriculum. Development and Psychopatholoy, 7, 117-136. doi:10.1017/S0954579400006374

Grietens, H., Onghena, P., Prinzie, P., Gadeyne, E., Van Assche, V., Ghesquière, P., et al. (2004). Comparison of mothers', fathers', and teachers' reports on problem behaviour in 5- to 6-yearold children. Journal of Psychopathology and Behavioural Assessment, 26, 137-146. doi:10.1023/ B:JOBA.0000013661.14995.59

Hautmann, C., Hoijtink, H., Eichelberger, I., Hanisch, C., Plück, J., Walter, D., et al. (2009). One year follow-up of a parent management training for children with externalizing behaviour problems in the real world. Behavioural and Cognitive Psychotherapy, 37, 379-396. doi:10.1017/ S135246580999021X

Harter, S. (1982). The perceived competence scale for children. Child Development, 53, 87-97. doi:10.2307/1129640

Hendrickx, M., Crombez, G., Roeyers, H. and de Castro, B. (2003). Psychometrische evaluatie van de Nederlandstalige versie van de Agressie Beoordelingsschaal van Dodge en Coie (1987) [Psychometric evaluation of the Dutch version of Dodge and Coie's (1987) Aggression Rating Scale]. Tijdschrift voor Gedragstherapie, 36, 33-43. 
Horsley, T. A., de Castro, B. and van der Schoot, M. (2010). In the eye of the beholder: eye-tracking assessment of social information processing in aggressive behaviour. Journal of Abnormal Child Psychology, 38, 587-599. doi: 10.1007/s10802-009-9361-x

Hudley, C. and Graham, S. (1993). An attributional intervention to reduce peer directed aggression among African-American boys. Child Development, 64, 124-138. doi:10.2307/1131441

Jones, D. J., Forehand, R. and Beach, S. R. H. (2000). Maternal and paternal parenting during adolescence: forecasting early adult psychosocial adjustment. Adolescence, 35, 513-531. doi:10.1037/ 0012-1649.16.3.241

Kellam, S. G. and van Horn, Y. V. (1997). Life course development, community epidemiology, and preventive trials: a scientific structure for prevention. American Journal of Community Psychology, 25, 177-188. doi:10.1023/A:1024610211625

Kendall, P. C. (1999). Clinical significance. Journal of Consulting and Clinical Psychology, 67, 283284. doi:10.1037/0022-006X.67.3.283

Kratochwill, T. R. and Shernoff, E. S. (2004). Evidence-based practice: promoting evidencebased interventions in school psychology. School Psychology Review, 33, 34-48. doi:10.1521/ scpq.18.4.389.27000

Kumpfer, K. L. and Alvarado, R. (1995). Strengthening families to prevent drug use in multi-ethnic youth. In G. Botvin, S. Schinke and M. Orlandi (Eds.), Drug Abuse Prevention with Multi-Ethnic Youth (pp. 255-294). Thousand Oaks, CA: Sage Publications, 1995.

Ladd, G. W. and Profilet, S. M. (1996). The child behaviour scale: a teacher-report measure of young children's aggressive, withdrawn, and prosocial behaviours. Developmental Psychology, 32, 10081024. doi:10.1037/0012-1649.32.6.1008

La Greca, A. M., Silverman, W. K. and Lochman, J. E. (2009). Moving beyond efficacy and effectiveness in child and adolescent intervention research. Journal of Consulting and Clinical Psychology, 77, 373-382. doi:10.1037/a0015954

Lemerise, E. A. and Arsenio, W. F. (2000). An integrated model of emotion processes and cognition in social information processing. Child Development, 71, 107-118. doi:10.1111/1467-8624.00124

Lipsey, M. W. and Wilson, D. B. (2001). Practical Meta-Analysis. Thousand Oaks, CA: Sage.

Lochman, J. E., Burch, P. R., Curry, J. F. and Lampron, L. B. (1984). Treatment and generalization effects of cognitive-behavioural and goal-setting interventions with aggressive boys. Journal of Consulting and Clinical Psychology, 52, 915-916.

Lochman, J. E. and Conduct Problems Prevention Research Group (1995). Screening of child behaviour problems for prevention programs at school entry. Journal of Consulting and Clinical Psychology, 63, 549-559. doi:10.1037//0022-006X.63.4.549

Lochman, J. E. and Wells, K. C. (2002a). Contextual social-cognitive mediators and child outcome: a test of the theoretical model in the Coping Power program. Development and Psychopathology, 14, 945-967. doi:10.1017/S0954579402004157

Lochman, J. E. and Wells, K. C. (2002b). The Coping Power program at the middle-school transition: universal and indicated prevention effects. Psychology of Addictive Behaviours, 16, S40-S54. doi:10.1037/0893-164X.16.4S.S40

Loman, S. L., Rodriguez, B. J. and Horner, R. H. (2010). Sustainability of a targeted intervention package: first step to success in Oregon. Journal of Emotional and Behavioural Disorders, 18, 178191. doi: $10.1177 / 1063426610362899$

Matthys, W. and Lochman, J. E. (2005). Social problem solving in aggressive children. In M. McMurran and J. McGuire (Eds.), Social Problem Solving and Offending (pp. 51-66). Chichester: Wiley.

McCartney, K. and Rosenthal, R. (2000). Effect size, practical importance, and social policy for children. Child Development, 71, 173-180. doi: 10.1111/1467-8624.00131

McConaughy, S. H. and Skiba, R. (1993). Comorbidity of externalizing and internalizing problems. School Psychology Review, 22, 421-436. 
McMahon, R. J., Bierman, K. L., Coie, J. D., Dodge, K. A., Greenberg, M. T., Lochman, J. E., et al. (1999). Initial impact of the Fast Track prevention trial for conduct problems: I. the high-risk sample. Journal of Consulting and Clinical Psychology, 67, 631-647. doi:10.1037/0022-006X.67. 5.631

Moffit, T. E. (1993). Adolescence limited and life-course-persistent antisocial behaviour: a developmental taxonomy. Psychology Review, 100, 674-701.

Muthén, B. O. (2000). Methodological issues in random coefficient growth modeling using a latent variable framework: application to the development of heavy drinking. In J. Rose, L. Chassin, C. Presson and J. Sherman (Eds.), Multivariate Applications in Substance Use Research: new methods for new questions (pp.113-140). Hillsdale, NJ: Erlbaum.

Muthén, B. and Kaplan, D. (1992). A comparison of some methodologies for the factor analysis of non-normal Likert variables: a note on the size of the model. British Journal of Mathematical and Statistical Psychology, 45, 19-30. doi:10.1037//0033-295X.100.4.674

Ogles, B. M., Lunnen, K. M. and Bonesteel, K. (2001). Clinical significance: history, application, and current practice. Clinical Psychology Review, 21, 421-446. doi:10.1016/S0272-7358(99)00058-6

Patterson, G. R. (2002). The early developmental of coercive family process. In J. B. Reid, G. R. Patterson and J. Snyder (Eds.), Antisocial Behaviour in Children and Adolescents: developmental theories and models for intervention (pp. 25-44). Washington, DC: American Psychological Association.

Patterson, G. R., Reid, J. B. and Dishion, T. J. (1992). A Social Learning Approach: IV. antisocial boys. Eugene, OR: Castalia.

Prinzie, P., Onghena, P. and Hellinckx, W. (2005). Parent and child personality traits and children's externalizing problem behaviour from age 4 to 9 years: a cohort-sequential latent growth curve analysis. Merrill-Palmer Quarterly, 51, 335-366. doi:10.1353/mpq.2005.0017

Rausch, J. R., Maxwell, S. E. and Kelly, K. (2003). Analytic methods for questions pertaining to a randomized pretest, posttest, follow-up design. Journal of Clinical Child and Adolescent Psychology, 32, 467-486. doi:10.1207/S15374424JCCP3203_15

Reid, J. M. and Webster-Stratton, C. (2001).The Incredible Years parent, teacher, and child intervention: targeting multiple areas of risk for a young child with pervasive conduct problems using a flexible, manualized treatment program. Cognitive and Behavioural Practice, 8, 377-386. doi:1077-7229/01/377-38651.00/0

Reinke, W. M., Splett, J., Robeson, E. and Offutt, C. (2009). Combining school and family interventions for the prevention and early intervention of disruptive behaviour problems in children: a public health perspective. Psychology in the Schools, 46, 33-43. doi:10.1002/pits. 20352

Salmivalli, C. (2001). Feeling good about oneself, being bad to others? Remarks on selfesteem, hostility, and aggressive behaviours. Aggression and Violent Behaviour, 6, 375-393. doi:10.1016/S1359-1789(00)0012-4

Salmivalli, C., Kärnä, A. and Poskiparta, E. (2011) Counteracting bullying in Finland: the KiVa program and its effects on different forms of being bullied. International Journal of Behavioural Development, 35, 405-411. doi:10.1177/0165025411407457

Salmivalli, C., Kaukiainen, A., Kaistaniemi, L. and Lagerspetz, K. M. (1999). Self-evaluated self-esteem, peer-evaluated self-esteem, and defensive egotism as predictors of adolescents' participation in bullying situations. Personality and Social Psychology Bulletin, 25, 1268-1278. doi:10.1177/0146167299258008

Saxena, S., Jané-Llopis, E. and Hosman, C. (2006). Prevention of mental and behavioural disorders: implications for policy and practice. World Psychiatry, 5, 5-14.

Scott, S. (2005). Do parenting programmes for severe child antisocial behaviour work over the longer term, and for whom? One year follow-up of a multi-centre controlled trial. Behavioural and Cognitive Psychotherapy, 33, 403-421. doi:10.1017/S135246580500233X 
Scott, S., Knapp, M., Henderson, J. and Maughan, B. (2001). Financial cost of social exclusion: follow up study of antisocial children into adulthood. British Medical Journal, 323, 191-194. doi:10.1136/bmj.323.7306.191

Shores, R. E., Jack, S. L., Gunter, P. L., Ellis, D. N., DeBriere, T. J. and Wehby, J. H. (1993). Classroom interactions of children with behaviour disorders. Journal of Emotional and Behavioural Disorders, 1, 27-39. doi:10.1177/106342669300100106

Silvia, E. S. and Thorne, J. (1997). School-Based Drug Prevention Programs: a longitudinal study in selected school districts. Research Triangle Institute, Research Triangle, NC. Unpublished manuscript.

Slough, N. M., McMahon, R. J. and Conduct Problems Prevention Research Group (2008). Preventing serious conduct problems in school-age youth: the Fast Track Program. Cognitive and Behavioural Practice, 15, 3-17. doi: 1077-7229/08/003-017\$1.00/0

Stevens, G. W. J. M. and Vollebergh, W. A. M. (2008). Mental health in migrant children. The Journal of Child Psychology and Psychiatry, 49, 276-294. doi:10.1111/j.1469-7610.2007.01848.x

Stice, E., Shaw, H., Bohon, C., Marti, C. N. and Rohde, P. (2009). A meta-analytic review of depression prevention programs for children and adolescents: factors that predict magnitude of intervention effects. Journal of Consulting and Clinical Psychology, 77, 486-503. doi:10.1037/ a0015168

Stoltz, S., van Londen, M., Deković, M., de Castro, B. and Prinzie, P. (in press). Individually delivered indicated school-based interventions on externalizing behaviour: a meta-analysis. International Journal of Behavioural Development.

Tolan, P. H. and Gorman-Smith, D. (2002). What violence prevention can tell us about psychopathology. Development and Psychopathology, 14, 713-729.

Veerman, J. W., Straathof, M. A. E., Treffers, P. D. A., van den Bergh, B. and Ten Brink, L. T. (1997). Handleiding Competentiebelevingsschaal voor Kinderen (CBSK). Lisse: Swets and Zeitlinger.

Verhulst, F. C., van der Ende, J. and Koot, H. M. (1997). Handleiding voor de Teacher Report Form $(T R F)$ : Nederlandse versie [Manual for the Teacher Report Form (TRF): Dutch version]. Rotterdam,The Netherlands: Afdeling Kinder en Jeugdpsychiatrie, Sophia Kinderziekenhuis/Academisch Ziekenhuis Rotterdam/Erasmus Universiteit Rotterdam.

Vitaro, F., Brendgen, M. and Tremblay, R. E. (2002). Reactively and proactively aggressive children: antecedent and subsequent characteristics. Journal of Child Psychology and Psychiatry, 43, 495-506. doi: $10.1177 / 0165025406059968$

Walker, H. M., Horner, R. H., Sugai, G., Bullis, M., Sprague, J. R., Bricker, D., et al. (1996). Integrated approaches to preventing antisocial behaviour patterns among school-age children and youth. Journal of Emotional and Behavioural Disorders, 4, 193-256. doi:10.1177/ 106342669600400401

Wilson, S. J. and Lipsey, M. W. (2006). The Effects of School-based Social Information Processing Interventions on Aggressive Behaviour. Part II: selected or indicated pull-out programs. Campbell Collaboration systematic review available at: CampbellCollaboration.org.

Wilson, S. J. and Lipsey., M. W. (2007). School-based interventions for aggressive and disruptive behaviour: update of a meta-analysis. American Journal of Preventive Medicine, 33, 130-143. doi:10.1016/j.amepre.2007.04.011

Yasui, M. and Dishion, T. J. (2007). The ethnic context of child and adolescent problem behaviour: implications for child and family interventions. Clinical Child and Family Psychology Review, 10, 137-179. doi:10.1007/s10567-007-0021-9 \}

Yoon, J., Hughes, J., Gaur, A. and Thompson, B. (1999). Social cognition in aggressive children: a metaanalytic review. Cognitive and Behavioural Practice, 6, 320-331. doi:1077-7229/99/32033151.00/0 